\title{
Oak Resprouting Survival and Competition for 19 Years after Wildfire in the Republic of Korea
}

\author{
Jeonghwan Kim ${ }^{1}$, Joo-Hoon Lim ${ }^{2}$, Moonhyun Shin ${ }^{3}{ }^{\circledR}$, Seung-Hyun Han ${ }^{3}(\mathbb{C}$ \\ and Wonseok Kang ${ }^{1, *}$ \\ 1 Division of Forest Resource Management and Restoration, National Institute of Forest Science, \\ Seoul 02455, Korea; biostatistics@korea.kr \\ 2 Haemil Institute of Forest Ecology and Silvics, Seoul 02490, Korea; forefire@naver.com \\ 3 Research Center for Endangered Species, National Institute of Ecology, Yeongyang 36531, Korea; \\ geography@korea.ac.kr (M.S.); aryian@naver.com (S.-H.H.) \\ * Correspondence: wons4457@korea.kr; Tel.: +82-2-961-2632
}

Received: 1 April 2020; Accepted: 26 April 2020; Published: 3 May 2020

\begin{abstract}
In the Republic of Korea, forest fire occurred at a rate of more than 400 events $\mathrm{yr}^{-1}$ from 2000 to 2016, and the burned areas are concentrated in the eastern coastal region. In this region, pine forest is extensively distributed, and pine forest is converted to oak forest through natural succession or stump-sprout regeneration following forest fires. However, there is a lack of research on oak competition and survival during the regeneration process in burned areas. Therefore, this research was carried out to evaluate the effects of oak survival ratio of Quercus serrata (glandbearing oak), Q. variabilis (oriental oak), and Q. mongolica (Mongolian oak) in burned areas. The investigation plots were set to survey tree height, diameter at breast height, sprout survival, and composition in Goseong-gun, Kangwon province, Republic of Korea. The mean tree heights of $Q$. serrata and Q. variabilis were approximately $9.8 \mathrm{~m}$ and $9.1 \mathrm{~m}$, respectively, which were higher than the approximately $5.8 \mathrm{~m}$ heights of $Q$. mongolica stands 18 years after a forest fire, and the trend for tree diameter at breast height was the same for all three species stands. In the early stage of regeneration after the forest fire, the survival probability of the Q. serrata sprouts decreased at a rate of 1.7-2.0 times higher than that of other oak species in the Q. serrata-dominant stands, and this tendency was found to the survival probability in $Q$. variabilis-dominant stands as well. The median survival time of $Q$. variabilis sprouts in the Q. variabilis-dominant stands was approximately 10.1 years, which was similar to $Q$. serrata-dominant stands. However, the dominant stand of Q. mongolica was different from that of other dominant stands since the stand mostly located in the ridge and the upper part of the mountain where topography and soil conditions were considerably dissimilar from the other stands. The decision of dominant species seems to be determined by the survival and occurrence of sprouts during the early stage in post-fire regenerated oak forests. Therefore, it would be more desirable to coppice sprout for dominant species productivity and rapid dominance after a forest fire.
\end{abstract}

Keywords: survival ratio; burned area; oak forest; post-fire; sprout competition

\section{Introduction}

In East Asia, forest fires are a very important cause of disturbance in forest ecosystems due to their influence on the forest and its environment, and fires are known to be a main cause of secondary succession [1-3]. Especially in the Republic of Korea, it is a common phenomenon that forests of Pinus densiflora (Korean red pine), P. thunbergii (black pine), and other conifers are replaced by oak dominant forests after forest fire [4]. 
In the Republic of Korea, approximately 440 forest fires have occurred, and approximately 2650 hectares have been burned annually during the last 16 years (2000-2016) [5,6]. Considering that an average of 237 forest fires occurred in the 1980s (1100 ha of damage) and an average of 336 forest fires occurred in the 1990s (1400 ha of damage), annual occurrence has increased over time $[7,8]$. This seems to be related to household income and leisure time growth because most of the forest fires occurred due to accidental human activity (1990s: 82.2\%, 2000s: 87.4\%) [5,9].

In particular, the east coast region has relatively higher winter temperatures and lower spring humidity than other regions in Korea due to topographical and climatic factors such as the Föhn phenomenon and oceanic climate. Also, many areas of the region consist of pine (P. densiflora) forests in the crown layer, and Quercus spp. in the understory layer, which are likely to lead to large forest fire damage $[10,11]$.

The Goseong region is located in the East Coast region of Korea. In the Goseong region, the forest has mainly consisted of P. densiflroa that is more sensitive to forest fires than other species (Quercus spp.). This species displays thin bark, high volatile compound content, flammability, and is evergreen [12-15]. As a result, policy support and technical research have been continuously carried out to predict and prevent large-scale forest fires. From 2012 to September 2018, the number of large-scale forest fires was only six cases [5]. However, there are ecosystem changes and succession processes that occur post-fire. In addition, studies on the prediction of forest fires and prevention of forest fires have been conducted. However, studies of the forest ecosystem changes and succession processes after forest fires are lacking [16].

The forest fire-damaged area was changed from pine forest to various postfire ecosystems that are naturally regenerated stands and plantations, and the soil chemical properties were altered [17,18]. In the Republic of Korea, natural regeneration was performed in areas that prioritized diversity and ecological management, and artificial regeneration was performed mainly in areas aimed at economic feasibility through forestry production, soil erosion control, and landslide prevention [19]. Following past forest fire disasters, most burned areas have been restored by focusing on pine afforestation. Although interest in natural regeneration after the forest fire disasters in 1996 and 2000 has increased, most of them were restored through artificial regeneration. There is a lack of detailed research on the survival of natural oak and forest vertical structures to prevent secondary damage, such as landslides.

Quercus spp. is widely distributed in not only Korea but also in other northern hemisphere countries that including China, Japan, Indonesia, Mexico, South-eastern USA, and Europe [20]. In the case of Korea, high abundance is related to naturally regenerated Q. acutissima (sawtooth oak), Q. mongolica (Mongolian oak), Q. variabilis (oriental oak), Q. serrata (glandbearing oak), Q. dentate (Korean oak), and Q. aliena (oriental white oak) after forest fires. These species are deciduous broadleaf tall trees that dominate temperate forests in Northeastern Asia [21,22]. In the Republic of Korea, most deciduous Quercus species are widely distributed in the middle and northern regions as small pure forest or mixed forest with other deciduous or conifer trees. However, $Q$. mongolica could make relatively large pure forests in some areas of high altitude [22]. Although the vertical distribution of the Quercus spp. varies with latitudinal position, the average distribution altitude of Q. mogolica in Korea is about $700 \mathrm{~m}$ above sea level (ASL) while Q. variabilis and Q. serrata are about $400 \mathrm{~m}$ ASL. $Q$. mongolica generally fits ridges or upper slopes with a higher altitude than $Q$. variabilis and $Q$. serrata, whilst $Q$. variabilis prefers a middle or upper slope [22,23].

The forest consisted of oak species in the overstory, and its natural regeneration is inhibited by the growth of various species such as Phyllostachys edulis (moso bamboo), Liquidambar formosana (Formosan gum), Prunus brachypoda, and Cyclocarya paliurus (sweet tea tree) in the understory and by high rodent densities and high acorn removal rates beneath the oak canopies [18,24]. Q. mongolica and $Q$. variabilis can be described as long-lived pioneer species because they often require large stand disturbances, such as forest fire, landslides, and thinning, to regenerate successfully from seeds $[25,26]$. Otherwise, stump sprouts mainly occur in degraded land, such as silviculturally thinned and forest 
fire-damaged areas in secondary succession processes. Stump sprouts are important in Quercus spp. reforestation in the burned area. However, the sprouts have growth limitations [18,27].

The competition of naturally regenerated Quercus spp. is divided into between-individual and within-individual. In the case of between-individual competition, oak outcompetes Pinus densiflora except in barren areas, such as ridges. Oak can grow under the canopy of red pine. However, red pine is shade intolerant $[28,29]$. In the case of multiple sprouts from a tree, a within-individual relationship occurs in the oak species. Stump sprout is a secondary reboot in oak species. Some studies have shown that resprouts in the early stage of forest development after a disturbance gain a competitive advantage by utilizing the stump [30] and hence grew disproportionately more height than sprouts emerging from seeds [31]. However, in the later stages of forest development, the resprouts grow disproportionately less than single-stem sprouts because they experience more intense competition with dense polycormons [32,33]. According to the previous studies, the coppice management of multiple stump-sprouts influences the improvement of volume, height growth, and survival [34,35]. In particular, vertical position is important because of species composition and growth. As the upper layer develops, the depth of the middle and lower vegetation decreases [36]. In other words, biotic factors mainly consist of competitions between-species or between-individuals and relationships with microbes.

The objective of this study was to understand regeneration characteristics of naturally regenerated oak forest in the Eastern coast of the Korean peninsula during 19 years after the forest fire. Specifically, to figure out and which Quercus species were dominant in the oak forest as time passed, sprouting patterns including overstory composition, growth, and development of the major oak species in the study sites were monitored. Since most of the burned areas in the Republic of Korea have been restored through artificial regeneration, it will help not only to understand post-fire regeneration processes in these oak forests, but also to develop alternative post-fire management options for these regions.

\section{Materials and Methods}

\subsection{Study Site Description and Survey to Tree Growth}

In the Goseong region on the eastern coast of the Republic of Korea, many forests were lost by the "Goseong forest fire (3834 ha)" in 1996 and the "Eastern coast forest fire (23,794 ha)" in 2000. These were accidental fires caused by human action. In the Goseong region, the annual average temperature was approximately $12.2^{\circ} \mathrm{C}$, and the annual average precipitation was $1402.2 \mathrm{~mm}$ from 1981 to 2010 by the table of climatological standard normals [37]. The altitude of the study sites ranged from 51 to $166 \mathrm{~m}$. In this region, the pine forest has wide distribution, and many pine forests mainly consist of Pinus densiflora in overstory (crown layer) and broadleaf trees such as Q. mongolica, Q. variabilis, Q. serrata, Q. dentata, Alnus japonica (Japanese alder), Fraxinus rhynchophylla (ash), Castanea crenata (Korean chestnut), etc. in the understory of the unburned area [11]. In contrast, the overstory of the study sites was composed of naturally regenerated Quercus species, mainly Q. mongolica Fisch. Ex Ledeb., Q. variabilis Blume, Q. serrata Murray, Q. acutissima Carruth., etc. on the naturally regenerated stand in the burned area [38]. This experiment was performed to confirm the overstory dominant and competition of species in naturally regenerated stands after two forest fires (1996 and 2000).

The three study sites were selected to monitor the growth of naturally regenerated plants as soon as forest fire occurrence. One study site consisted of five-square survey plots $\left(10 \times 10 \mathrm{~m}, 100 \mathrm{~m}^{2} \mathrm{plot}^{-1}\right)$. Initially, the five survey plots were located in the valley, but one survey plot in the valley was turned into a mountain stream three years later because the waterway had been changed due to landslide. Therefore, a total of 14 survey plots sites has been remained (Figure 1; valley: 4 plots, mountainous facing: 5 plots, ridge: 5 plots).

The number of individual oaks (stump sprouts per ground area) was measured ten times (2001, 2002, 2003, 2004, 2005, 2006, 2008, 2010, 2010, and 2018) from 2001 to 2018. Sprout height, root collar diameter $(\mathrm{RCD})$, and diameter at breast height (DBH) of Quercus spp. were measured 
only 2 and 18 years after the forest fire (2002 and 2018) in 14 study plots during the fall season (from September to November). In each survey plot, the dominant species was determined by the number of sprouts, that consisted of the forest crown layer after 18 years from the forest fire. The criteria for the survival ratio were based on a study after forest fire damage [27]. The survival and composition ratios were calculated by stump sprout number through elapsed time after the forest fire. For example, the composition ratio was calculated to specified species per total sprout number of Quercus spp. by Equations (1) and (2).

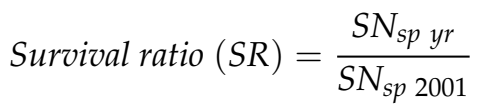

$$
\begin{aligned}
& \text { Compoistion ratio }(C R)=\frac{S N_{s p} y r}{S N_{\text {total } y r}}
\end{aligned}
$$

where $S N_{s p ~ y r}$ denotes sprouts number of each species and each year within plot, $S N_{s p} 2001$ is sprout number of each species at 2001, while $S N_{\text {total yr }}$ is sprouts number of the total each year within plot.
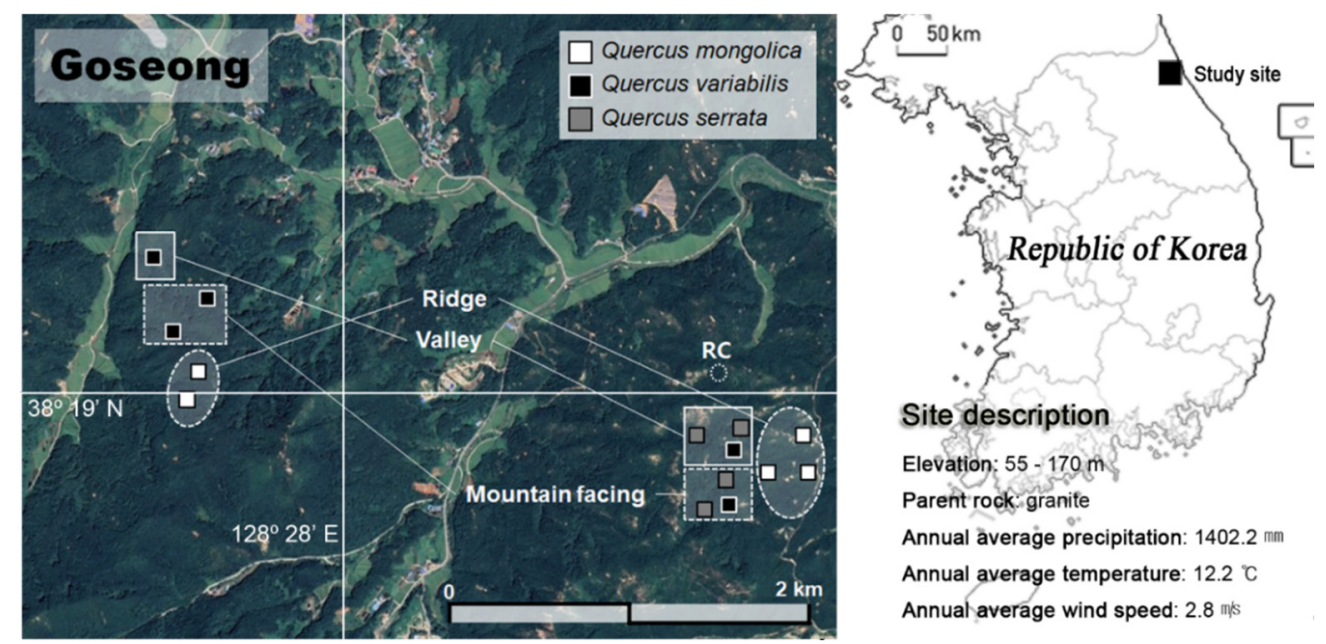

Figure 1. The geographic location and the study site. White filled squares, Quercus mongolica (Mongolian oak) dominant stand; Black filled squares, Quercus variabilis (oriental oak) stand; Gray filled squares, Quercus serrata (glandbearing oak) dominant stand; RC, right censoring.

\subsection{Analysis}

Each subpopulation and the time-series viability data of each Quercus spp. were analyzed by Kaplan-Meier survival analysis and Gehan-Breslow methods. The Gehan-Breslow test is a non-parametric test using the chi-square test. Further, it assumes that early survival times are known more accurately than later survival times, and the required sample number is less than log-rank and the Tarone-Ware method $[39,40]$. We selected this method because the change of survival was important in the initial stage after a forest fire.

Multiple comparisons of survival curves among oak species were confirmed by the Holm-Sidak adjustment method [41] using Sigmaplot 12.5 (SYSTAT Inc., Chicago, IL, USA). The probability density function was calculated as the survival function multiplexed by the hazard function. Further, the differences in tree growth and tree density among dominant-species were verified by non-parametric methods (Kruskal-Wallis test and Dunn-Bonferroni method). All data analyses used SPSS 18.0 (IBM, North Castle, NY, USA), except for survival analysis. 


\section{Results}

\subsection{Sprout Growth and Composition over Time}

The mean tree heights of the dominant species in each stand, eighteen years after a forest fire, are shown in Table 1 . The Q. serrata- and $Q$. variabilis-dominant stands were similar at 9.8 (Standard deviation, SD: 3.8) and 9.1 (SD: 4.3) $\mathrm{m}$ in height, however these values were higher than 6.0 (SD: 2.8) $\mathrm{m}$ height in $Q$. mongolica $(p<0.05$, H-value $=28.703)$. The mean DBH of $Q$. serrata was the highest at 14.3 (SD: 4.1$) \mathrm{cm}$, followed by Q. variabilis at 11.6 (SD: 4.3) $\mathrm{cm}$ and Q. mongolica at 5.9 (SD: 2.5) $\mathrm{cm}(p<0.05, \mathrm{H}$-value $=63.364)$. According to the Korean yield table [42] the DBH of Q. mongolica ranged from 8 to $15 \mathrm{~cm}$ at 20 years old, which is higher than the growth of $Q$. mongolica in the study site. Otherwise, the tree density of the dominant species was approximately 20,300 sprouts ha ${ }^{-1}$ in the $Q$. mongolica stand, which was the highest, followed by approximately 9100 sprouts ha ${ }^{-1}$ in the $Q$. serrata stand and approximately 8700 sprouts ha $^{-1}$ in the $Q$. variabilis stand $(p<0.05, \mathrm{H}$-value $=8.409$ ). In the trees above $2 \mathrm{~m}$ height, the composition ratio of dominant species occupying approximately 0.781 was $Q$. mongolica, followed by 0.371 in $Q$. serrata, and 0.216 in $Q$. variabilis.

In the year following the forest fire, most study sites began stump sprouting of oak species (Q. mongolica, $Q$. variabilis, and $Q$. serrata) at a rate of more than two hundred per plot, although the composition ratio was different among species. More than $90 \%$ of oak sprouts were in the range from 10 to $160 \mathrm{~cm}$ height after two years (Figure 2). Nine years after the forest fire, the number of Q. variabilis sprouts rapidly decreased from four to eight years, more than in other oak species (Figure 3). In total, the relative growth of $Q$. variabilis height was $1.1 \mathrm{~m}$ per year nine years after, which is higher than the $0.7 \mathrm{~m}$ of $Q$. serrata and $0.3 \mathrm{~m}$ of $Q$. mongolica $p<0.01)$.

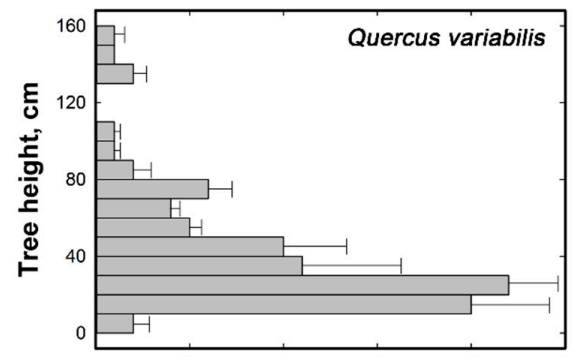

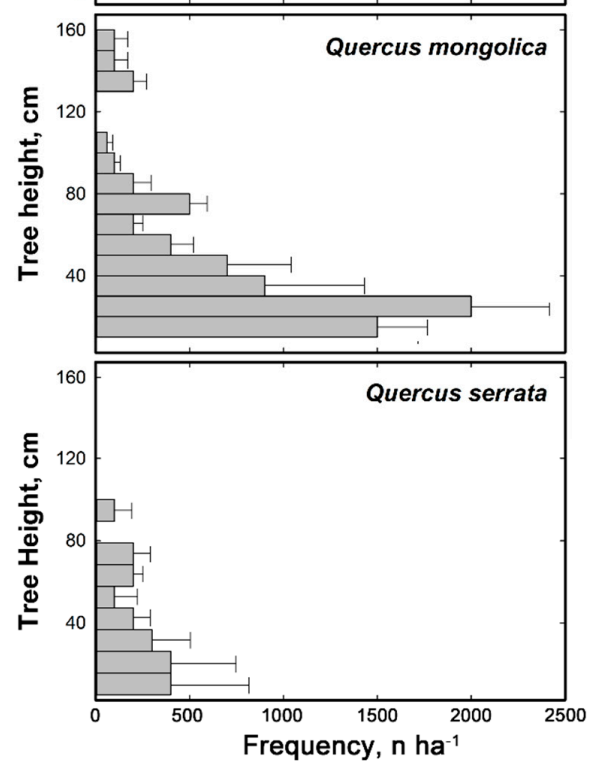

(a) 2 years

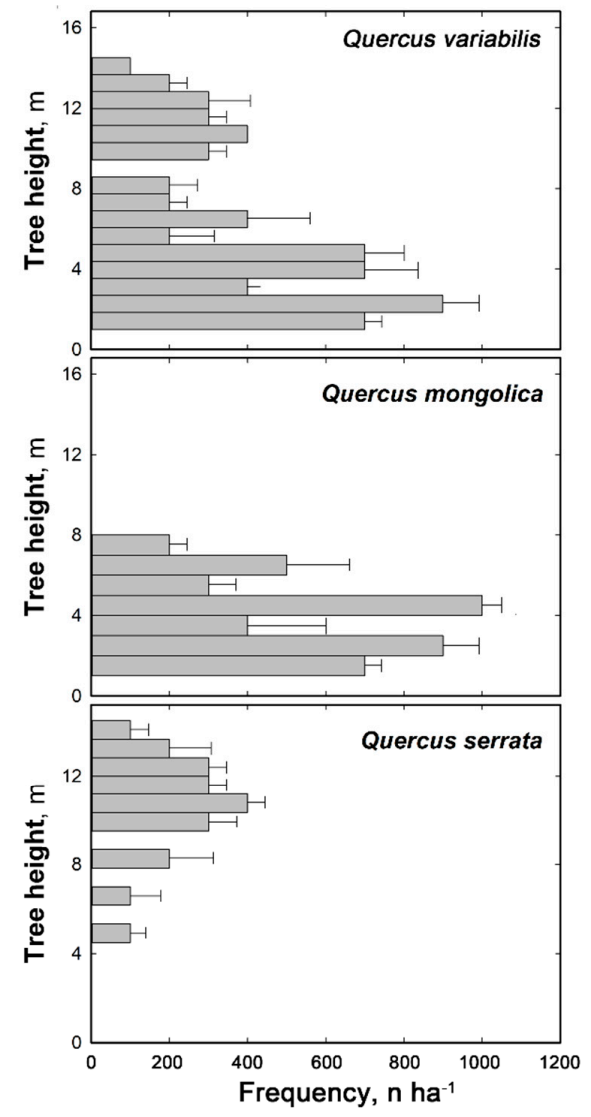

(b) 18 years

Figure 2. Change to the vertical distribution of oak species. in Q. serrata (glandbearing oak) stands as time passed. (a) 2 years after the forest fire; (b) 18 years after the forest fire. Error bar means standard error. 
(a) Quercus variabilis dominant stand

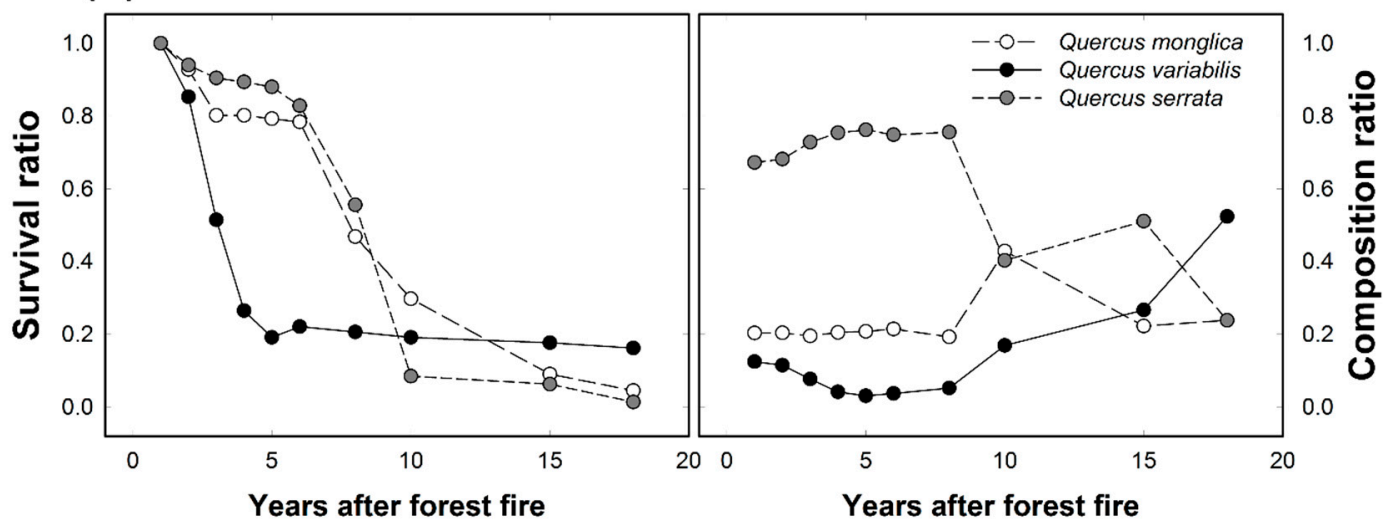

(b) Quercus serrata dominant stand

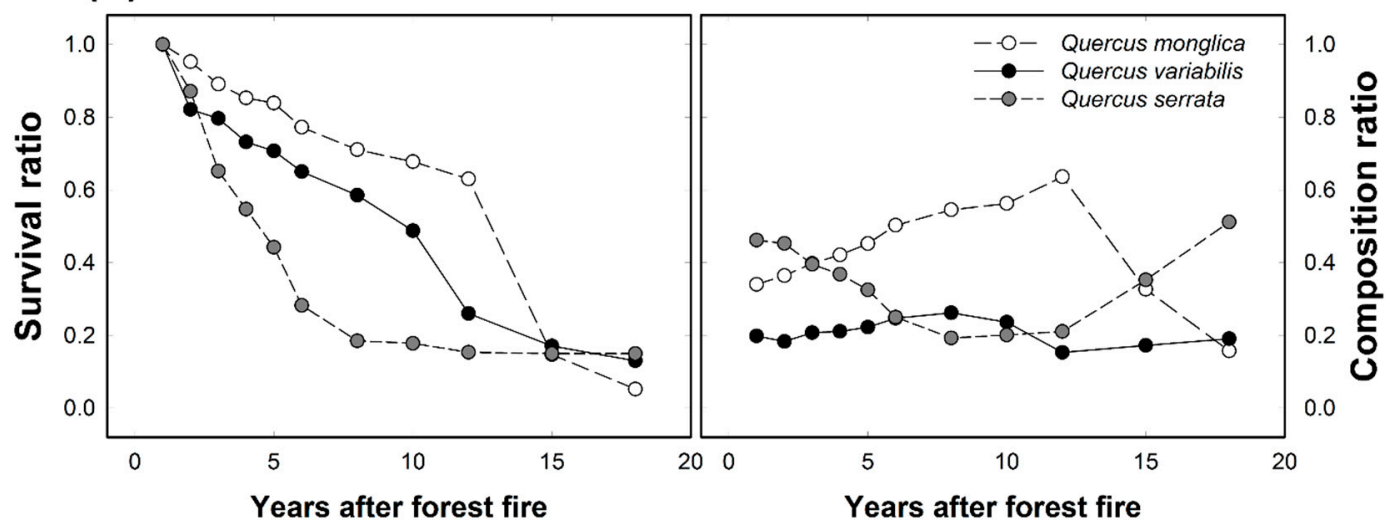

(c) Quercus mongolica dominant stand

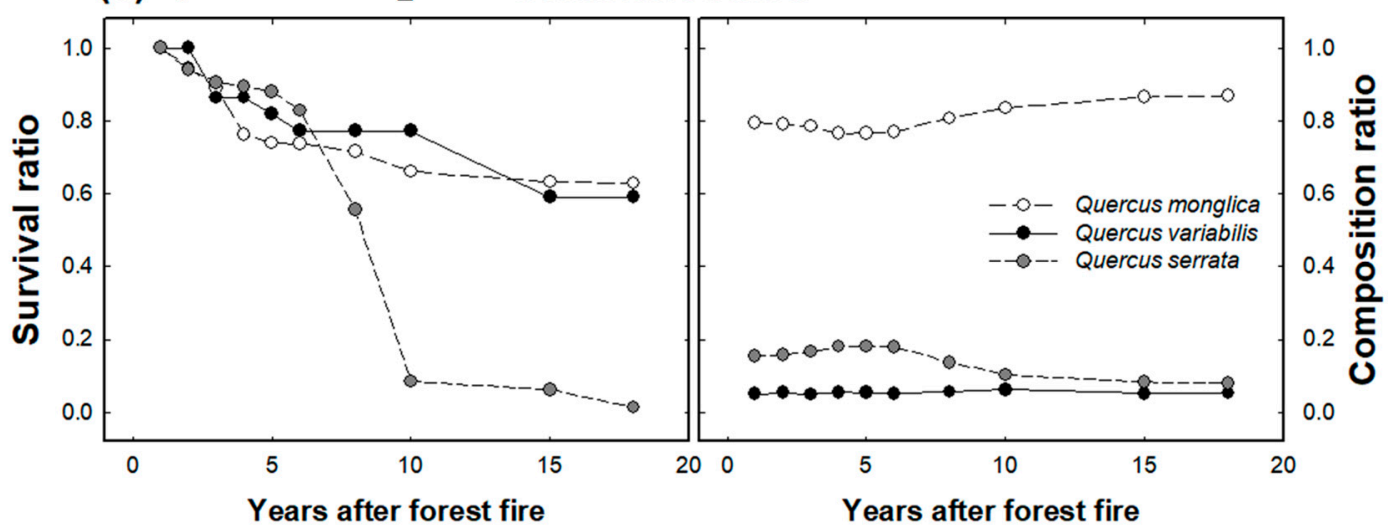

Figure 3. The survival ratio and composition ratio of (a) Quercus variabilis (oriental oak), (b) Quercus serrata (glandbearing oak) and (c) Quercus mongolilca (Mongolian oak) dominant stand during the 18 years after the forest fire. 
Table 1. The growth ${ }^{1}$ of oak in naturally regenerated stands during 18 years after forest fire.

\begin{tabular}{|c|c|c|c|c|}
\hline Stand & Species & Tree Height, m & Mean DBH, cm & $\begin{array}{l}\text { Tree Density, } \\
\text { Trees ha } \mathbf{h}^{-1}\end{array}$ \\
\hline \multirow{4}{*}{$\begin{array}{l}\text { Quercus variabilis } \\
\text { (oriental oak) }\end{array}$} & Quercus variabilis ${ }^{1}$ & $9.1(4.3)^{a}$ & $11.6(4.3)^{\mathrm{b}}$ & $870^{b}$ \\
\hline & Quercus mongolica ${ }^{1}$ & $4.5(2.9)$ & $5.4(2.4)$ & 670 \\
\hline & Quercus serrata ${ }^{1}$ & $4.7(2.9)$ & $4.1(3.0)$ & 1370 \\
\hline & Quercus dentate & $1.9(0.6)$ & $2.2(0.8)$ & 120 \\
\hline \multirow{4}{*}{$\begin{array}{l}\text { Quercus mongolica } \\
\text { (Mongolian oak) }\end{array}$} & Quercus mongolica $^{1}$ & $6.0(2.8)^{b}$ & $5.9(2.5)^{\mathrm{c}}$ & $2030^{a}$ \\
\hline & Quercus variabilis 1 & $4.9(2.0)$ & $7.1(3.2)$ & 130 \\
\hline & Quercus serrata 1 & $3.6(3.9)$ & $5.0(5.9)$ & 200 \\
\hline & Quercus dentate & $2.4(0)$ & $2.5(0)$ & 30 \\
\hline \multirow{5}{*}{$\begin{array}{c}\text { Quercus serrata } \\
\text { (glandbearing oak) }\end{array}$} & Quercus serrata $^{1}$ & $9.8(3.8)^{a}$ & $14.3(4.1)^{\mathrm{a}}$ & $910^{b}$ \\
\hline & Quercus variabilis 1 & $4.1(3.1)$ & $4.9(2.3)$ & 670 \\
\hline & Quercus mongolica ${ }^{1}$ & $2.9(2.4)$ & $3.8(2.9)$ & 330 \\
\hline & Quercus dentate & $2.1(1.5)$ & $2.3(1.3)$ & 170 \\
\hline & Quercus acutissima & $3.4(3.3)$ & $3.7(3.4)$ & 200 \\
\hline \multicolumn{2}{|c|}{ Kruskal-Wallis H-value ${ }^{1}$} & 28.703 & 63.364 & 8.409 \\
\hline
\end{tabular}

${ }^{1}$ When the tree height is more than $2 \mathrm{~m}$. Comparison of among growth and tree density of dominant species. Numbers in parentheses indicate the standard deviation. The different subscript with the number indicated to the significant difference between groups to Dunn-Bonferroni test at 0.05 levels.

\subsection{Survival Analysis of Oak Sprouts}

The sprout survival ratio (SSR) of Quercus variabilis was the highest (0.162) in the five Q. variabilis-dominant plots, followed by Q. mongolica (0.045) and Q. serrata site (0.014) 18 years after the forest fire. In $Q$. variabilis-dominant stands, the estimated survival probability of $Q$. variabilis sprouts ranged from 0.974 at 2 years to 0.0378 at 18 years, with a decrease of approximately 0.5 points during the first 8 years after the forest fire. The total censored percentage of this species was 0.038 over 18 years since the forest fire. The mean survival time of sprouts was approximately 10.062 (9.575-10.550 95\% CI) years in Q. variabilis, the lowest of the oak species, followed by approximately 12.875 (12.479-13.271 95\% CI) years in Q. mongolica and approximately $13.070(12.858-13.283$ 95\% CI) years in $Q$. serrata $(p<0.01)$.

In the case of Quercus serrata-dominant stands, the SSR of Q. serrata was the highest (0.150) in the four $Q$. serrata-dominant sites, followed by $Q$. serrata $(0.130)$ and $Q$. mongolica $(0.052) 18$ years after the forest fire. The survival ratio of $Q$. serrata sprouts decreased by approximately 0.7 points during the first eight years after the forest fire (0.95-0.27). The total censored percentage of this species was 0.038 . The mean survival time of $Q$. serrata sprouts was approximately $10.062(9.575-10.550$ $95 \% \mathrm{CI})$ years, which was the lowest of the oak species $(p<0.01)$. The sprout survival probability in $Q$. serrata-dominant stands was the same as in $Q$. variabilis-dominant stands.

Meanwhile, in Q. mongolica-dominant stands, the SSR of Q. mongolica was 0.628 higher than 0.132 in $Q$. serrata. The mean survival times of Quercus spp. sprout were approximately 14.402 (14.171-14.633 95\% CI) years in Q. mongolica, approximately 14.186 (13.693-14.680 95\% CI) years in Q. variabilis, and approximately 15.093 (14.228-15.958 95\% CI) years in Q. serrata. Furthermore, the sprout survival probability in Q. mongolica-dominant stands was different than that in Q. variabilisand $Q$. serrata-dominant stands, which were caused not only by sprouts of $Q$. serrata occurring in only one site but also by the number of $Q$. serrata sprouts occurring in $Q$. mongolica-dominant stands 18 years after the forest fire (see Figure 2). In addition, the Q. mongolica-dominant stand was located on the ridge and upper part of the mountain, and the soil physical and chemical properties were more substandard than found at other sites. 


\section{Discussion}

In the Q. variabilis-dominant stands, the average height of sprouts of $Q$. variabilis 18 years after the forest fire was approximately $9.1 \mathrm{~m}$, higher than other species; however, tree density was approximately 870 sprouts ha ${ }^{-1}$, lower than Q. serrata (1370 sprouts ha $\left.{ }^{-1}\right)$. According to the Korean yield table [42,43], the average tree height of $Q$. variabilis and Q. serrata are in the range of $8.4-12.4 \mathrm{~m}$ (Q. variabilis) and 6.8-8.5 $\mathrm{m}(Q$. serrata) at 20 years old, which are similar to these results. However, the tree height of Q. mongolica (average: $6.0 \mathrm{~m}$ ) is lower than the yield table that ranges from 8.2 to 10.8 . In the initial stage, the sprouting number of Quercus spp. was the highest at approximately 9870 sprouts ha ${ }^{-1}$ in Q. serrata, followed by Q. mongolica and Q. variabilis. During the first 8 years after the forest fire, the tree survival ratio of Quercus spp. rapidly decreased, which was fastest in Q. variabilis, followed by $Q$. serrata, and $Q$. mongolica. In the case of $Q$. serrata-dominant stands, the $Q$. serrata sprouts had within-individual competitions during the first eight years. As a result, the tree height growth of Q. serrata was higher than that of other species. Q. serrata covered an overstory 15 years after the forest fire. The density probability consisted of survival probability multiplied by hazard probability. Thus, the density probability means snapshot probability at a specific point in time. In addition, density changes hazard and survival, which are less sensitive than hazards (see Figure 4). The high increase of density function means high hazard at a specific time. Thus, the SSR of the dominant species rapidly decreased in the early stage (before 10 years), while the SSR of the suppressed trees rapidly changed after 10 years.

The height growth in low density stump sprouts was higher than that in high density [44]. In addition, the coppice management effect in the early stage after thinning on $Q$. variabilis forest increased productivity more than in the later stage [45]. In particular, the growth of the suppressed trees rapidly decreased 10 years after the forest fire in $Q$. variabilis- and $Q$. serrata-dominant stands, which appears to be caused by the fact that the dominant trees formed the overstory. Consequently, it seems resources such as water, light, and nutrients were not sufficiently supplied to all sprouts of the suppressed trees [46,47]. In addition, the precipitation levels were $1264 \mathrm{~mm}$ and 1283 $\mathrm{mm}$ in 2007 and 2010, respectively, lower than the climatological normal (1402 mm, 1981-2010) which corresponded to the period of the rapid decrease in the number of sprouts of the suppressed trees. The previous study showed that the quantity of oak sprouts was rapidly reduced when resources were not supplied properly $[48,49]$. Meanwhile, the tendency of $Q$. mongolica-dominant stands was different than that of $Q$. serrata and Q. variabilis stands. The height and DBH growth in Q. mongolica-dominant stand were lower than documented in the Korean yield table [43], smaller stature and smaller DBH may be due to geographical location. The Q. mongolica-dominant stands were located on the ridge or upper part of the mountain. Considering the work of Keim et al. [48], these topographical features and soil conditions may have negative effects not only on stump sprouting, but also on the height growth of other Quercus spp. with low competition.

It has been reported that $Q$. variabilis, $Q$. acutissima and $Q$. serrata are rapidly selected as the main sprouts rather than $Q$. mongolica and $Q$. dentate, and the dynamics are inversely correlated $[50,51]$. Additionally, the topography is a major factor in the growth of Quercus species that are dependent on dominant coverage [52]. In this process, the difference in sprouting ability of each oak species was affected by geographical location which is consistent with previous articles [36,44]. In the case of Q. mongolica forest after the forest fire, the tree density of Q. mongolica was continuously the highest. This result is similar to that in a California black oak forest where, after disturbances, stump sprouts regenerated more rapidly than other sprouts, and seeds generated 13 years after a forest fire [53]. 
(a) Quercus variabilis dominant stand
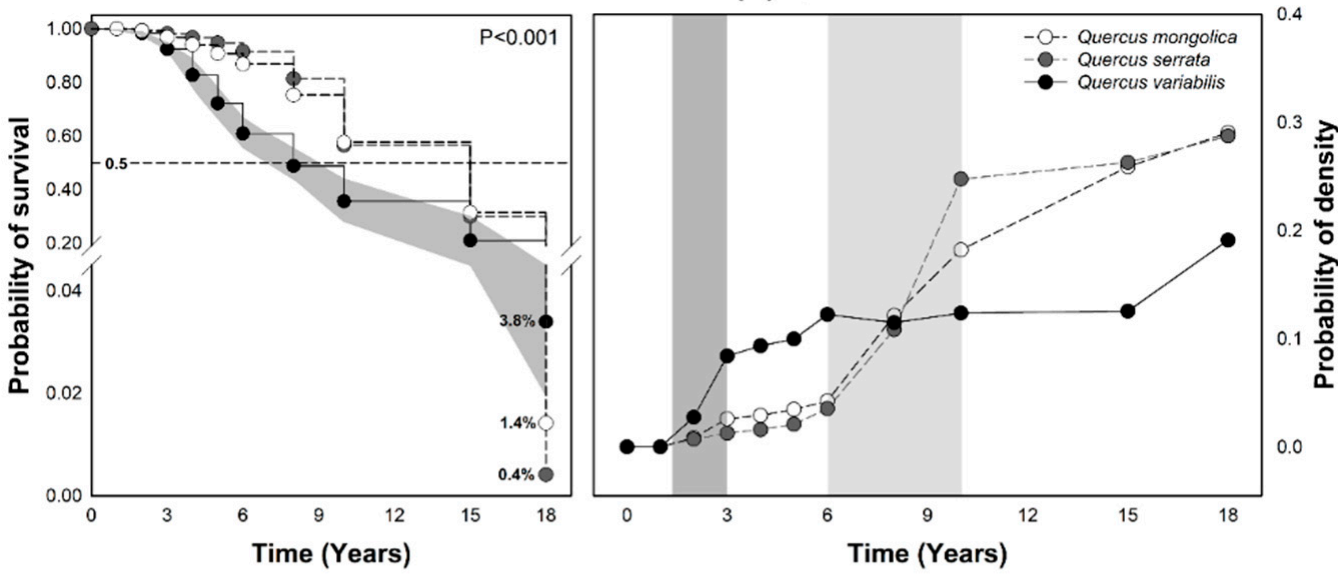

(b) Quercus serrata dominant stand
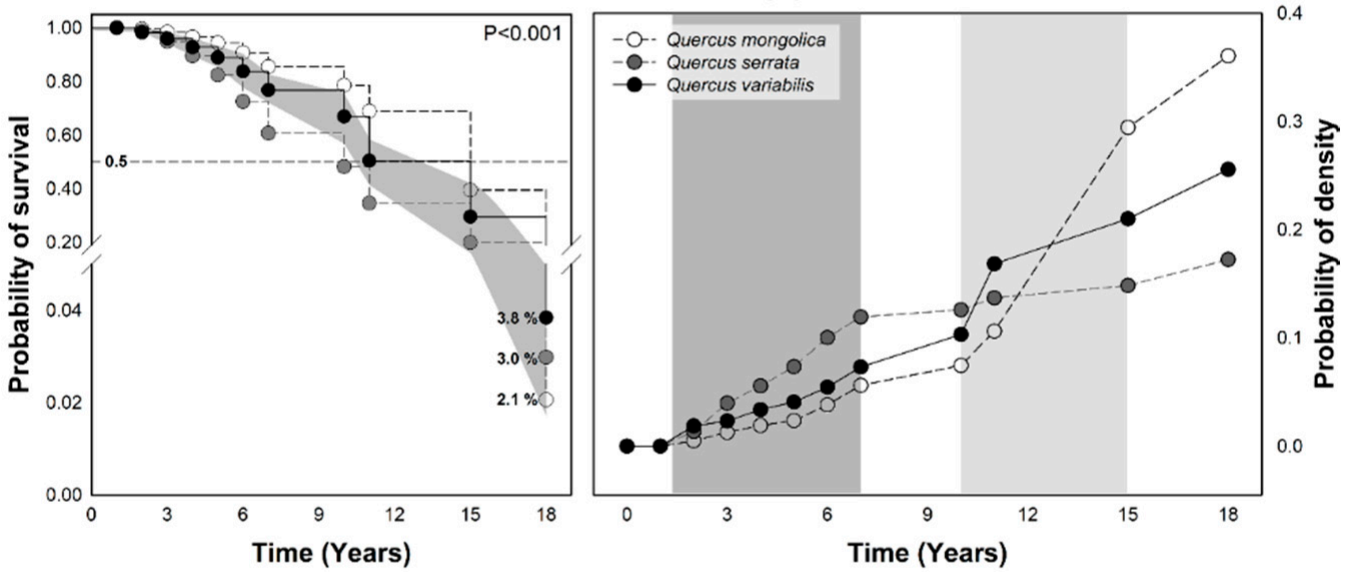

(c) Quercus mongolica dominant stand
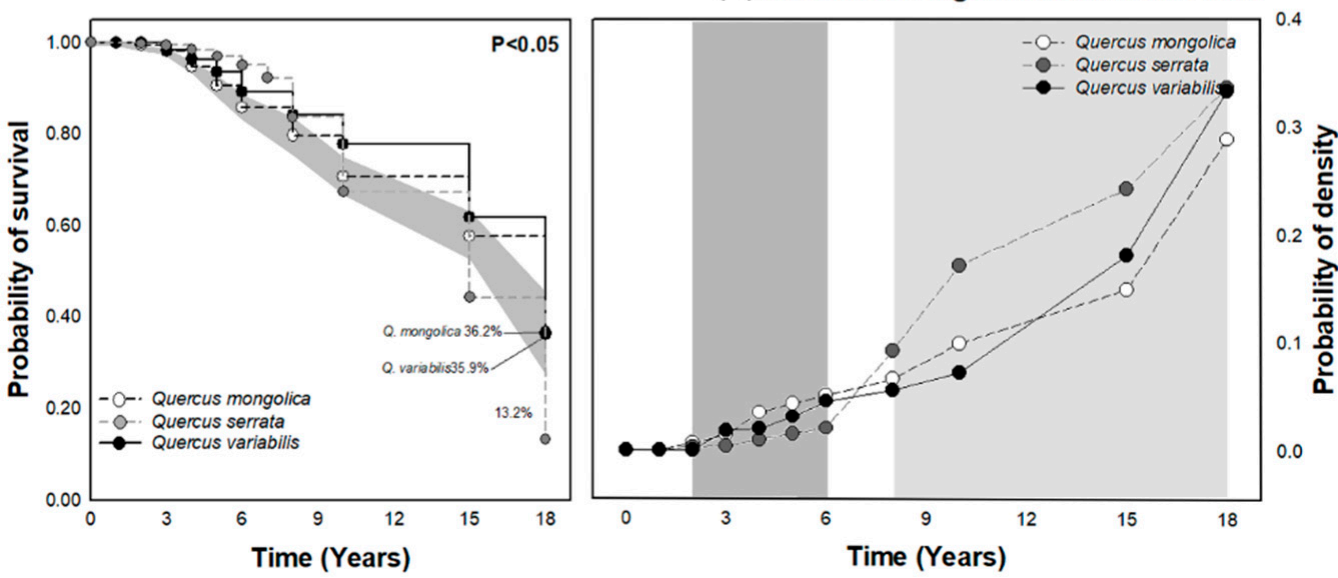

Figure 4. Sprout survival and density probability of each Quercus spp. (oak) in the naturally regenerated forest. (a), Quercus variabilis-dominant stand; (b), Quercus serrata-dominant stand; (c), Quercus mongolica-dominant stand. In the left two figures, the gray color means a $95 \%$ confidence interval of the dominant species. In the right two figures, the dark gray color means interval with high density probability of dominant species and light gray means interval with high density probability non-dominant species.

Meanwhile, the effects of topographic conditions on each species stand might be unexpectedly stronger than their survival and growth characteristics on species competition. It was consistent with the previous study that $Q$. mongolica forests are more widely distributed in ridge areas or higher 
elevation of Republic of Korea than Q. serrata and Q. variabilis forests [54,55]. In order to investigate the intact effect of species competition, further studies should be conducted under similar site conditions for each species. The mean tree height of the Q. mongolica stand was lower than that of the other stands, and it was difficult for certain species and individuals to grow vertically. The diameter before thinning was affected not only growth limitation of stump sprouts but also the relative growth rate after thinning in the oak forest [22,35], and clump growth and survival of Quercus nigra (water oak) were increased with overstory thinning intensity in a 28-year-old $Q$. nigra forest [56]. Stump sprouts have a low occurrence because oak trees are slow to grow and strive for survival compared to inter-individual competition [33]. Meanwhile, the high density of sprouts was reduced due to competition, but after the determination of the dominant relationship with the competition pressure, the growth increased, and this phenomenon led to vertical differentiation [30,31]. In the case of the Q. mongolica stand, competition between individuals was not cut-throat, but the growth was insufficient due to the soil inferiority, such that vertical differentiation seemed to be reduced. However, many studies have shown that oak growth caused by stump sprouting has marginal growth. Therefore, further studies and analysis of stump sprouting are needed.

\section{Conclusions}

Stump sprouting of oak is a common phenom and natural regeneration process in the Republic of Korea after a forest fire. The space available to each individual stump sprout influences not only the intensity of inter- and intra-specific competition, but also the growth of oak sprouts during the regeneration process after a forest fire. For this reason, this study was performed to determine the relationship between sprout density and species dominance in natural regeneration. The authors confirmed that high mortality due to competition in the first eight years is associated with dominance later in the burned area. As a result, when natural sprouting occurred with such high probability of density and the decrease of SSR at an early stage in Q. serrata and Q. variabilis, they lead to dominance. Thus, during the first eight years after a forest fire, it would be more desirable to stump sprouts of certain species for their productivity and rapid dominance. These results were used to predict stand change, which was natural domination selection and sprout growth through oak sprout viability in the early stage. Meanwhile, this result did not consider environmental conditions, such as topography, terrain location, and soil properties. Therefore, further research is needed to figure out the effects of these conditions.

Author Contributions: J.K. was responsible for study design, data analysis, and drafting this manuscript. J.-H.L. was responsible for initial design, and supervised the field survey. M.S. and S.-H.H. was responsible for field data collection, providing feedback, and revision to manuscript. W.K. was responsible for initial design and provided a major contribution to securing funding support, and providing feedback and revision to manuscript drafts. All authors have read and agreed to the published version of the manuscript.

Funding: This research was funded by the "Long-term Monitoring of Ecosystem Changes on Natural Regenerated Forest and Plantation in Forest Fire Damaged Area (FE-0500-2016-02)" of the Korean National Institute of Forest Science, Korea.

Acknowledgments: Thank you for the comments of Jae-hong Hwang, and an anonymous reviewer that significantly improved draft manuscripts. We thank all field assistance members, including Jae-Hyung Cho at the Korean National Institute for Forest Science.

Conflicts of Interest: The authors declare that have no conflict of interest.

\section{References}

1. Barnes, B.V.; Zak, D.R.; Denton, S.R.; Spurr, S.H. Forest Ecology, 4th ed.; Wiley: New York, NY, USA, 1998 ; p. 792.

2. Korea Forest Research Institute. Restoration of Fire Damaged Area; Korea Forest Research Institute (KFRI): Seoul, Korea, 1999; p. 173.

3. Fulé, P.; García-Arévalo, A.; Covington, W. Effects of an Intense Wildfire in a Mexican oak-pine forest. Forest Sci. 2000, 46, 51-61. [CrossRef] 
4. $\quad$ Choung, Y.; Lee, B.C.; Cho, J.H.; Lee, K.S.; Jang, I.S.; Kim, S.H.; Hong, S.K.; Jung, H.C.; Choung, H.L. Forest response to the large-scale east coast fires in Korea. Ecol. Res. 2004, 19, 43-54. [CrossRef]

5. Korea Forest Service. Forest Fire Statistical Yearbook; Korea Forest Service (KFS): Daejeon, Korea, 2018; p. 263. (In Korean without English abstract)

6. Korea Forest Service. Annual Statistics Report of Forest Fire; Semmunhwa: Seoul, Korea, 2016; p. 242. (In Korean without English abstract).

7. Lee, M.; Lee, S.; Lee, J.H. Study of the characteristics of forest fire based on statistics of forest fire in Korea. J. Korean Soc. Hazaard Mitigatioin 2012, 12, 185-192. (In Korean with English abstract). [CrossRef]

8. Korea Forest Service. The Occurrence of Forest Fire. KFS 2020. Available online: http://forset. go.kr/newkfsweb/kfi/kfs/frfr/selectFrfrStats.do?searchCnd=2010\&mn=KFS_02_02_01_05_01 (accessed on 11 February 2020).

9. Kim, S.S.; Lee, M.W. Analysis of forest fire based on statistics over the past 50 years in Korea. J. KOSHAM 2013, 13, 275-280. (In Korean with English abstract). [CrossRef]

10. Lim, J. Forest fire and meteorology of Eastern Korea. Korean J. Agric. For. Meteor. 2000, 2, 62-67. (In Korean with English abstract).

11. Lee, W.; Kim, S.; Bae, S.; Lee, J.; Shin, H.; Jung, M.; Moon, H.; Bae, E. Vegetation type and stand structure of Pinus densiflora forests in Kangwon northern regions in Korea. J. Agric. Life Sci. 2009, 43, 7-17. (In Korean with English abstract).

12. Kim, Y.; Shin, D. Volatile components and antibacterial effects of pine needle (Pinus densiflora S. and Z.) extracts. Food Microbiol. 2005, 22, 37-45. [CrossRef]

13. Shan, Y.; Liu, N.; Shu, L. Flammability ranking of foliage species by factor analysis of physical and chemical pyric properties. Fire Mater. 2008, 32, 371-382. [CrossRef]

14. Korea Forest Research Institute. Economy Species 1: Pinus Densiflora; Korea Forest Research Institute: Seoul, Korea, 2012; p. 250. (In Korean without English abstract)

15. Patra, J.; Kim, S.; Hwang, H.; Choi, J.; Baek, K. Volatile compounds and antioxidant capacity of the bio-oil obtained by pyrolysis of Japanese red pine (Pinus densiflora Siebold and Zucc.). Molecules 2015, 20, 3986-4006. [CrossRef]

16. National Science and Technology Information Service (NTIS), National R\&D Project in Korea. Available online: $\quad$ https://www.ntis.go.kr/ThSearchProjectList.do?gubun=link\&searchWord=\%EC $\% 82 \% \mathrm{~B} 0 \%$ EB\%B6\%88\&searchSentence=\&searchViewData=\&searchType=\&oldSearchWord=\%EC\%82\%B0\%EB\% B6\%88\&resultSearch=\&pageNumber $=4 \&$ ssoKnfSlct $=$ \&ascDesc $=$ ASC\&useYn=N\&oldQuery $=\% E C \%$ 82\%B0\%EB \%B6\%88\&oldAddQuery=\%26SN04\%3D2019\&dbt=project\&checkYn=\&searchOption16= \&pageYn=Y\&technologyClassification=ST\&directorySearch Year=\&directorySearchOption1= \&directorySearchOption2=\&directorySearchOption3=\&downloadTarget=project\&startRow =\&endRow= \&rqstPurpCd=\&infoPrctuseDes=\&layerChoice=\&sort=RANK\%2FDESC\&pageSize=20\&navigation $1 \%$ 5B0\%5D=2019 (accessed on 27 February 2020).

17. Certini, G. Effects of fire on properties of forest soils: A review. Oecologia 2005, 143, 1-10. [CrossRef] [PubMed]

18. Ryu, S.R.; Choi, H.T.; Lim, J.H.; Le, L.K.; Ahn, Y.S. Post-fire restoration plan for sustainable forest management in south Korea. Forests 2017, 8, 188-201. [CrossRef]

19. Korea Forest Research Institute. Post-Fire Restoration to Establish a Healthy and Sustainable Forest Ecosystem, English Edition; KFRI: Seoul, Korea, 2010; p. 60.

20. Denk, T.; Grimm, G.; Manos, P.; Deng, M.; Hipp, A. An Updated Infrageneric Classification of the Oaks: Review of Previous Taxonomic Schemes and Synthesis of Evolutionary Pattern. Oaks Physiological Ecology Exploring the Functional Diversity of Genus Quercus L. Tree Physiol. 2017, 13-38. [CrossRef]

21. Dolezal, J.; Song, J.S.; Altman, J.; Janecek, S.; Cerny, T.; Srutek, M.; Kolbek, J. Tree growth and competition in a post-logging Quercus mongolica forest on Mt. Sobaek, South Korea. Ecol. Res. 2009, 24, 281-290. [CrossRef]

22. Korea Forest Research Institute. Economic Tree Species (2) Oak; KFRI: Seoul, Korea, 2012; p. 250. (In Korean without English abstract)

23. Lee, D. Forest Ecological Management; Seoul University: Seoul, Korea, 2012; p. 471, (Korean only).

24. Da, L.J.; Kang, M.M.; Song, K.; Shang, K.K.; Yang, Y.C.; Xia, A.M.; Qi, Y.F. Altitudinal zonation of human-disturbed vegetation on Mt. Tianmu, Eastern China. Ecol. Res. 2009, 24, 1287-1299. [CrossRef] 
25. Xu, N.; Guo, W.; Liu, J.; Du, N.; Wang, R. Increased nitrogen deposition alleviated the adverse effects of drought stress on Quercus variabilis and Quercus mongolica seedlings. Acta Physiol. Plant. 2015, 37, 107. [CrossRef]

26. Wang, S.; Xuan, L.; Guo, C. Community ecology of poplar-birch forest in China. J. Northeast For. Univ. 1996, 7, 7-11. [CrossRef]

27. Xue, Y.; Zhang, W.; Zhou, J.; Ma, C.; Ma, L. Effects of stump diameter, stump height, and cutting season on Quercus variabilis stump sprouting. Scand. J. For. Res. 2013, 28, 223-231. [CrossRef]

28. Dey, D.C.; Gardiner, E.S.; Schweitzer, C.J.; Kabrick, J.M.; Jacobs, D.F. Underplanting to sustain future stocking of oak (Quercus) in temperate deciduous forests. New For. 2012, 43, 955-978. [CrossRef]

29. Lee, W.K.; van Gadow, K.; Chung, D.-J.; Lee, J.L.; Shin, M.Y. DBH growth model for Pinus densiflora and Quercus variabilis mixed forests in central Korea. Ecol. Modell. 2004, 176, 187-200. [CrossRef]

30. Liu, Z.; Fang, S.; Liu, D.; Yu, M.; Tang, L.T. Influence of thinning time and density on sprout development, biomass production and energy stocks of sawtooth oak stumps. For. Ecol. Manag. 2011, 262, $299-306$. [CrossRef]

31. Mostacedo, B.; Putz, F.E.; Fredericksen, T.S.; Villca, A.; Palacios, T. Contribution of root and stump sprouts to natural regeneration of a logged tropical dry forest in Bolivia. For. Ecol. Manag. 2009, 258, 978-985. [CrossRef]

32. Kauppi, A.; Kiviniitty, M.; Ferm, A. Growth habits and crown architecture of Betula pubescens Ehrh. of seed and sprout origin. Can. J. For. Res. 1998, 18, 1603-1613. [CrossRef]

33. Pytte, P.L.; Fisher, U.F.; Suchomel, C.; Gärtner, S.M.; Bauhus, J. The effect of harvesting on stump mortality and re-sprouting in aged oak coppice forests. For. Ecol. Manag. 2013, 289, 18-27. [CrossRef]

34. Canellas, I.; Del, M.; Roig, S.; Montero, G. Growth response to thinning in Quercus pyrenaica Willd. coppice stand in Spanish central mountain. Ann. For. Sci. 2004, 61, 243-250. [CrossRef]

35. Lim, J.; Ji, D.; Lee, Y.G.; Lee, M. Study on the management system of oak coppice forest on forest fire site. J. Korean. For. Soc. 2009, 98, 652-658. (In Korean with English abstract).

36. Swaim, J.T.; Dey, D.C.; Saunders, M.R.; Weigel, D.R.; Thornton, C.D.; Kabrick, J.M.; Jenkins, M.A. Predicting the height growth of oak species (Quercus) reproduction over a 23-year period following clearcutting. For. Ecol. Manag. 2016, 364, 101-112. [CrossRef]

37. Korea Meteorological Administration. Climatological Normals of Korea (1981 2010); Korea Meteorological Administration: Seoul, Korea, 2011; p. 678.

38. Song, J.H.; Lim, J.H.; Kwon, J.; Yun, C.W. Comparison vegetation structure change between 2003 and 2014 in forest fire damaged are of Bihwjin basin, Samcheok in Korea. J. Korean For. Soc. 2017, 106, 150-168. [CrossRef]

39. Kortet, R.; Hedrick, A. A behavioural syndrome in the field cricket Gryllus integer: Intrasexual aggression is correlated with activity in a novel environment. Biol. J. Linn Soc. Lond. 2007, 91, 475-482. [CrossRef]

40. Ahnn, S.; Anderson, S. Sample size determination in complex clinical trials comparing more than two groups for survival endpoints. Statist. Med. 1998, 17, 2525-2534. [CrossRef]

41. Sdak, Z. Retangular confidence regions for the mean of multivariate normal distributions. J. Am. Stat. Assoc. $1967,62,626-633$.

42. Korea Forest Research Institute. Forest Tree Volume, Biomass and Yield Table; KFRI: Pocheon-si, Korea, 2012; p. 261, (Korean only).

43. National Institute of Forest Science. Yield Table for Actual Forest; National Institute of Forest Science: Seoul, Korea, 2016; p. 54, (Korean only).

44. Dinh, T.T.; Kajikawa, C.; Akaji, Y.; Yamada, K.; Matsumoto, T.K.; Makimoto, T.; Miki, N.H.; Hirobe, M.; Sakamoto, K. Stump sprout dynamics of Quercus serrata Thunb. and Q. acutissima Carruth. four years after cutting in an abandoned coppice forest in Western Japan. For. Ecol. Manag. 2019, 435, 45-56. [CrossRef]

45. Wang, X. Assessment and Management of Oak Coppice Stands in Shangnam County, Southern Shaanxi Province, China. Ph.D. Thesis, München Technical University, München, Germany, 2013; p. 573.

46. Staaf, H.; Stjernquist, I. Seasonal dynamics, especially autumnal retranslocation of nitrogen and phosphorus in foliage of dominant and suppressed trees of beech. Fagus Sylvatica. Scand. J. For. Res. 1986, 1, 333-342. [CrossRef]

47. Peri, P.L.; Gargaglione, V.; Pastur, M. Above- and belowground nutrient storage and biomass accumulation in marginal Nothofagus antarctica forests in Southern Patagonia. For. Ecol. Manag. 2008, 255, 2502-2511. [CrossRef] 
48. Keim, R.F.; Chambers, J.L.; Hughes, M.S.; Dimov, L.D.; Conner, W.H.; Shaffer, G.P.; Gardiner, E.S.; Day, J.W.J. Long-term success of stump sprouts in high-graded bald cypress-water tupelo swamps in the Mississippi delta. For. Ecol. Manag. 2006, 234, 24-33. [CrossRef]

49. Khan, M.L.; Tripathi, R.S. Effects of stump diameter, stump height and sprout density on the sprout growth of four tree species in burnt and unburnt forest plots. Acta Oecol. 1989, 10, 303-316.

50. Brevik, E.C.; Fenton, T.E.; Horton, R. Effect of daily soil temperature fluctuations on soil electrical conductivity as measured with the geonics EM-38. Precis. Agric. 2004, 5, 145-152. [CrossRef]

51. Ebihara, K.; Masahiro, T.; Tomoaki, I.; Kouichi, O. Development of Agricultural Soil Sterilization Using Ozone Generated by High Frequency Dielectric Barrier Discharge. J. Adv. Oxid. Technol. 2005, 33-40. [CrossRef]

52. Son, S.; Kwon, K.; Jeong, T. Productive structure and net production of Quercus mongolica forest in Mt. Taehwa (Kwangju, Kyonggi-do). For. Bioenergy 2002, 21, 76-82. (In Korean with English abstract).

53. Hammett, E.J.; Ritchie, M.W.; Berrill, J.P. Resilience of California black oak experiencing frequent fire: Regeneration following two large wildfires 12 years apart. Fire Ecol. 2017, 13, 91-103. [CrossRef]

54. Kim, J.; Yim, Y.; Kil, B. Classification and pattern analysis of the forest vegetation in Daedunsan provincial park, Korea. Korean J. Ecol. 1988, 11, 109-122.

55. Kim, J.; Yim, Y. Distribution patterns of species populations along the environmnetal gradients in Mt. Moak Provincial Park, Korea. Korean J. Ecol. 1992, 15, 365-375.

56. Gardiner, E.S.; Helmig, L.M. Development of water oak stump sprouts under a partial overstory. New For. 1997, 14, 55-62. [CrossRef]

(C) 2020 by the authors. Licensee MDPI, Basel, Switzerland. This article is an open access article distributed under the terms and conditions of the Creative Commons Attribution (CC BY) license (http://creativecommons.org/licenses/by/4.0/). 